\title{
Ovarian cancer: involvement of the matrix metalloproteinases
}

\author{
Linah Al-Alem and Thomas E Curry Jr \\ Department of Obstetrics and Gynecology, University of Kentucky Medical Center, 800 Rose Street, Room C355, \\ Lexington, Kentucky 40536-0293, USA \\ Correspondence should be addressed to T E Curry; Email: tecurry@uky.edu
}

\begin{abstract}
Ovarian cancer is the leading cause of death from gynecologic malignancies. One of the reasons for the high mortality rate associated with ovarian cancer is its late diagnosis, which often occurs after the cancer has metastasized throughout the peritoneal cavity. Cancer metastasis is facilitated by the remodeling of the extracellular tumor matrix by a family of proteolytic enzymes known as the matrix metalloproteinases (MMPs). There are 23 members of the MMP family, many of which have been reported to be associated with ovarian cancer. In the current paradigm, ovarian tumor cells and the surrounding stromal cells stimulate the synthesis and/or activation of various MMPs to aid in tumor growth, invasion, and eventual metastasis. The present review sheds light on the different MMPs in the various types of ovarian cancer and on their impact on the progression of this gynecologic malignancy.

Reproduction (2015) 150 R55-R64
\end{abstract}

\section{Ovarian cancer}

Ovarian cancer is the fifth leading cause of cancer death in women today according to the National Cancer Institute's (NCl) 2014 statistics. It is diagnosed in $\sim 22000$ women in the USA and accounts for at least 14000 deaths each year. Approximately two-thirds of women are diagnosed with stage III or stage IV of the disease, wherein the 5 -year survival rate is $25-30 \%$ or less, as compared to an 80-95\% 5-year survival rate for those with stage I or stage II ovarian cancer (Tingulstad et al. 2003).

There are three main types of ovarian cancer, including epithelial ovarian cancer, sex cord stromal tumors, and germ cell tumors. Of these, epithelial tumors account for about $90 \%$ of ovarian cancers (Table 1), and they are the leading cause of death from gynecological malignancies (Zhang et al. 2005, Choi et al. 2007). Sex cord stromal and germ cell tumors account for the remaining $\sim 10 \%$ (Choi et al. 2007). Generally, germ cell tumors present at an earlier age than epithelial ovarian cancer, affecting women in their late teens and early twenties. The average age of women with epithelial ovarian cancer is around 60 years old, and it therefore affects mostly peri- or post-menopausal women. Different epithelial tumors are classified according to the cell types found in the reproductive tract, and they include serous, mucinous, endometrioid, clear cell, and transitional cell types (Table 2).
The risk factors associated with the development of ovarian cancer are based on an increased number of ovulatory cycles, and they include nulliparity, early menarche with late menopause, increasing age, and the use of fertility drugs, although the relationship of the latter to ovarian cancer remains controversial (Rossing et al. 1994, Venn et al. 1999, Dor et al. 2002). Consequently, the incidence of ovarian cancer decreases with multiparity, the use of oral contraceptives, and breastfeeding (Collaborative Group on Epidemiological Studies of Ovarian Cancer 2008, Koshiyama et al. 2014). The observation that ovarian cancer increases with ovulation rate led to the 'incessant ovulation' hypothesis, which was first proposed by Fathalla (1971). According to that hypothesis, follicular rupture results in an inflammatory reaction that damages the ovarian surface epithelial cells in the vicinity of the ovulatory stigma through DNA-altering reactive oxygen species. Such alterations result in potentially mutagenic lesions, such as P53 or BRCA (Fathalla 2013, Koshiyama et al. 2014). Hence, a family history of ovarian cancer is a risk factor mainly because of the genetic mutations of BRCA 1 and BRCA2 as well as the presence of Lynch syndrome, which is hereditary $(\mathrm{NCl})$. These mutagenic insults to the ovarian surface epithelial cells then direct the cells toward a malignant fate. Other risk factors may include the use of talc and obesity $(\mathrm{NCl})$.

Histological similarities between serous cancers that arise in the ovaries and those that arise in the fallopian 
Table 1 Classification and incidence of the major types of ovarian cancer.

\begin{tabular}{ll}
\hline Type of ovarian cancer & Incidence \\
Epithelial & $90 \%$ \\
Germ cell & $5 \%$ \\
Sex cord & $5 \%$ \\
Primary peritoneal & Rare \\
\hline
\end{tabular}

tubes have led to the proposal that some ovarian cancers are of fallopian tube origin (Crum et al. 2007a). Ovulation results in the distal fallopian epithelial cells being bathed with follicular fluid that contains high levels of steroids, inflammatory cytokines, and reactive oxygen species. All of these molecules could lead to mutagenic changes in the tubal epithelial cells, which then give rise to metastasis to the ovary and result in ovarian carcinoma (Crum et al. 2007b, Fathalla 2013).

These cellular changes set in motion the events that change the phenotype in ovarian or fallopian tube cells from benign to malignant and allow the tumor to grow, acquire vascularization, and gain the characteristics that lead to metastasis. Chief among these changes in the tumor cell is the ability to modify the surrounding extracellular matrix (ECM). The ECM is a key regulatory component in cellular physiology that provides an environment for cell migration, allows differentiation, and, in some cases, decides the ultimate fate of cell survival or cell death (Birkedal-Hansen et al. 1993). In order for tumor cells to grow, invade, and metastasize, it is crucial for the cells to be able to disrupt the surrounding ECM. This matrix degradation allows tumor cells to proliferate, easily detach from their primary site, extravasate, and invade other tissues (Schropfer et al. 2010). Matrix metalloproteinases (MMPs) are known to be important players in the physiological process of cancer progression (John \& Tuszynski 2001, Kessenbrock et al. 2010). The present review focuses on the recent literature on the involvement of the MMPs in ovarian cancer.

\section{The MMP system}

The MMP family in humans encompasses 23 related proteolytic enzymes that share common structural and functional similarities (Kleiner \& Stetler-Stevenson 1993, Murphy et al. 1999). These functional similarities include: i) the presence of zinc in the active site of the catalytic domain, ii) the synthesis of the enzyme in an inactive or latent form, iii) the activation of the latent zymogen, and iv) the inhibition of enzyme action by both serum-borne and tissue-derived metalloproteinase inhibitors in the extracellular environment. Based on their structural similarities, the MMPs are classified into four broad categories: collagenases, gelatinases, stromelysins, and membrane type enzymes (MT-MMPs), as illustrated in Fig. 1. However, a few MMPs exhibit different characteristics and are classified outside of these four broad classes, as discussed later in the present review.

Studies have shown that the MMPs act on a diverse group of ECM components, including the collagens, gelatins, fibronectins, and laminins (Murphy et al. 1999, Nagase \& Woessner 1999, Curry \& Osteen 2003, Berchuck et al. 2009). Yet the MMPs also exhibit activity toward other MMPs, growth factors, and cytokines, such as insulin-like growth factor (IGF) binding proteins (IGFBP), epidermal growth factor, tumor necrosis factor $\alpha$, and substance P (Sternlicht \& Werb 2001). The ability of these enzymes to cleave binding proteins as well as growth factors has expanded the repertoire of MMP actions to include the modulation of cell growth. In the tumor microenvironment, MMPs may be the key regulatory point in disrupting the balance between growth and antigrowth signals, and they may thereby influence the bioavailability of growth factors to stimulate tumor cell growth, as reviewed by Kessenbrock et al. (2010). For example, one of the main pathways that is typically altered in cancer cells is the transforming growth factor-beta (TGF- $\beta$ ) receptor system, which leads to increased invasion and the metastatic potential of cancer cells (Massague 2008). TGF- $\beta$ is activated via proteolytic conversion by MMPs, such as MMP2, MMP9, and MMP14 (Mu et al. 2002). The ability of the MMPs to turn on TGF- $\beta$ activity suggests that MMPs have indirect tumor-promoting effects (Kessenbrock et al. 2010).

The regulation of ECM turnover and cell growth by MMPs is rigorously controlled by MMP inhibitors. There are two major classes of inhibitors, the serum-borne and the tissue-derived inhibitors (Curry \& Osteen 2003). The serum-borne inhibitors include the macroglobulins, which have a potent ability to inhibit a broad range of proteinases. The tissue inhibitors of metalloproteinases, or TIMPs, are a family of four inhibitors that are locally produced, and they specifically inhibit MMPs. The TIMPs differ in their selectivity for different MMPs. For example, TIMP2 has a high affinity for MMP2, whereas

Table 2 Major cellular subtypes of ovarian epithelial cancer.

\begin{tabular}{lll}
\hline Type of epithelial cancer & Subtypes & Incidence \\
Serous & Cystomas, benign cystadenomas, cystadenomas, cystadenocarcinomas & $7 / 10$ \\
Mucinous & Cystomas, benign cystadenomas, cystadenomas, cystadenocarcinomas & $1 / 10$ \\
Endometrioid & Benign cysts, adenocarcinomas, endometrioid tumors, adenocarcinomas & $1 / 20$ \\
Clear cell & Cystomas, benign cystadenomas, cystadenomas, cystadenocarcinomas & $3 / 100$ \\
Undifferentiated/unclassified & Tumors that do not fall into any of the other groups & $1 / 10$ \\
\hline
\end{tabular}




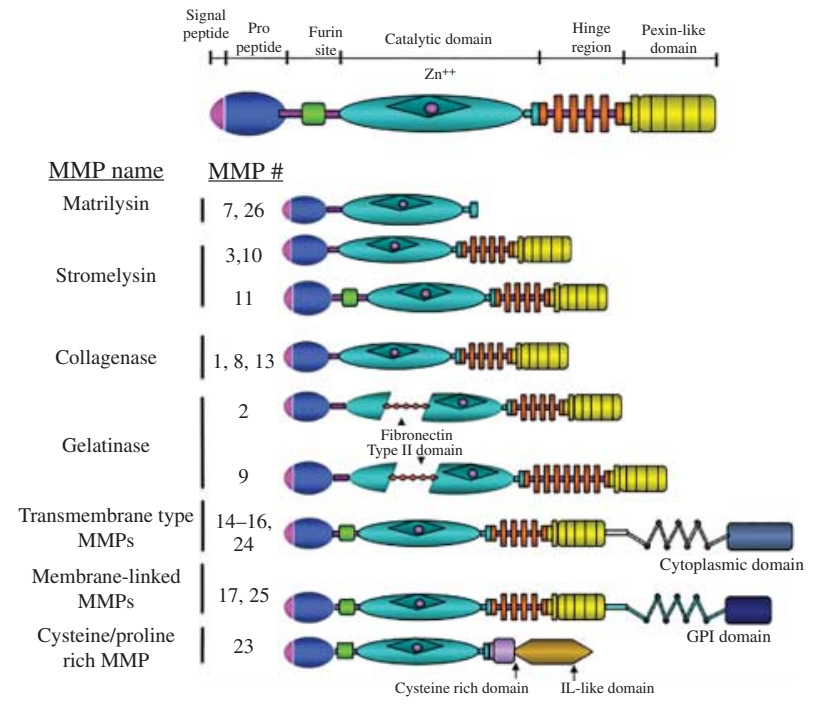

Figure 1 Schematic of the different classes of MMPs. The overall structure of the MMPs contains a signal peptide, a pro-peptide, a furin site, a catalytic domain, a hinge region, and a pexin-like domain. The gelatinases differ insofar as they also contain a fibronectin type II domain. Matrilysins lack the pexin-like domain, and the membrane types contain a cytoplasmic or GPI domain. Figure modified from Nagase \& Woessner (1999) and Curry \& Osteen (2003).

TIMP1 preferentially binds to MMP9 (Gomez et al. 1997). TIMP3 is able to inhibit the membrane type 1 MMP (MT1-MMP or MMP14), unlike TIMP1, which cannot act on MT1-MMP. However, unlike TIMP1 or TIMP2, TIMP3 is secreted and then bound to the ECM, and it has been suggested that the ECM allows TIMP3 to act as an additional regulatory stop point by working at the site of MMP action (Gomez et al. 1997).

\section{MMPs and ovarian cancer}

\section{The collagenases: MMP1, MMP8, MMP13}

The three collagenases share structural similarities and have the ability to act on a broad variety of substrates. Although all of the collagenases cleave fibrillar collagen, these proteases have different affinities toward type I, type II, and type III collagen. MMP14, which is a membrane type MMP, also acts on collagens and will be discussed in the membrane type MMP section later in the present review. The collagenases also have different mechanisms for reaching the extracellular environment (Nagase \& Woessner 1999, Borkakoti 2000). For example, MMP8 is predominately found in neutrophils, where it is synthesized and stored in granules until it is needed. Unlike MMP8, MMP1 and MMP13 are produced and secreted in a wide range of cell types in response to specific stimuli without being stored. The collagenases have been implicated in ovarian cancer because of their expression patterns, which are dependent on the stage and tumor type (Behrens et al. 2001, Hantke et al. 2003, Stadlmann et al. 2003). For example,
MMP1 and the gelatinase MMP9 were shown to be strongly expressed in both stromal and epithelial tumor cells of serous invasive carcinomas and to be upregulated in the fibroblastic stroma of borderline tumors, but they were shown to be expressed at very low levels in serous benign cystadenomas (Behrens et al. 2001).

In a herculean effort, Stadlmann et al. (2003) examined MMP expression in 302 patients using immunohistochemistry on tissue cylinder specimens. In their study, they collected 119 serous, 40 mucinous, 68 endometrioid, 16 undifferentiated, 16 mullerian, 24 clear cell, five malignant Brenner, ten sex cord, and four yolk sac tumors. The tumors were graded and correlated with prognosis and also processed for microarrays and immunohistochemistry. Numerous MMPs were expressed in all of the ovarian cancers as discussed in detail within each MMP class in the following sections. Interestingly, only MMP8 expression levels correlated with tumor grade, tumor stage, and a poor prognosis. MMP8 was up-regulated by interleukin-1 $\beta$, which suggests that that pro-inflammatory cytokines may promote the invasive potential of ovarian cancer by stimulating MMP8 expression.

Because MMP13 has been associated with ovarian cancer, it has been studied as a potential prognostic indicator. Hantke et al. (2003) investigated the protein levels of MMP13 in ascitic fluids of 30 patients with advanced ovarian cancer. Using an ELISA, they stratified MMP13 values into two subpopulations, one population with short survival (median 16 months) and one with long overall survival (median 36 months). MMP13 was shown to be associated with shorter survival. Thus, the levels of MMP13 in ascitic fluid may identify a patient's risk and potential survival outcome.

Overexpression of the MMPs may transduce the signals for tumor cell migration and invasion through a cell surface receptor that is coupled to $G$ proteins, protease-activated receptor 1 (PAR1). PAR1 is cleaved by MMP1, which promotes breast cancer migration and invasion (Boire et al. 2005). PAR1 has also been identified in ovarian cancer. Agarwal et al. (2008) identified a metalloprotease cascade, wherein proMMP1 was activated to MMP1, which in turn directly activated PAR1. This activation of MMP1-PAR1 induced the secretion of several angiogenic factors from ovarian carcinoma cells, which caused endothelial cell proliferation, endothelial tube formation, and migration (Agarwal et al. 2010) as well as epithelial ovarian cancer cell invasion (Wang et al. 2011a). Further investigation of PAR1 has demonstrated that serum levels of PAR1 are elevated in patients with epithelial ovarian cancer, but serum levels were not of predictive nor of prognostic value in that group of patients (Karabulut et al. 2014).

Polymorphisms in the MMP promoter may lead to the overexpression of MMPs in ovarian cancer. For example, Kanamori et al. (1999) reported that a guanine (G) insertion/deletion polymorphism within the promoter 
region of MMP1 possesses greater transcriptional activity, that the proportion of patients who contained the polymorphism was elevated in patients with ovarian cancer, and that MMP1 expression was elevated in ovarian cancer tissue. Subsequent investigation into the association between promoter polymorphisms and cancer risk has questioned the role of promoter mutations in the expression of MMP1 (Wenham et al. 2003, Li et al. 2006), but it has also indicated a possible association between polymorphisms in the MMP7, MMP8, MMP12, or MMP13 promoters and the susceptibility to epithelium ovarian cancer in various populations (Li et al. 2006, 2009, Arechavaleta-Velasco et al. 2014).

\section{The gelatinases: MMP2 and MMP9}

MMP2 and MMP9 have been extensively studied in cancer, and there is a plethora of literature that documents their expression in ovarian cancer and cancer progression. Hence, the overview in the present review highlights some of these findings and emphasizes their similarities and controversies. Brun et al. (2008, 2012) have extensively characterized the localization and expression levels of MMP2, MMP7, MMP9, and MT1 in different types and stages of ovarian cancer. They report that serous tumors express higher levels of MMP2, MMP7, and MMP9 as compared to mucinous tumors. However, in the surrounding stromal tissue, the expression of MMP2 and MMP9 did not differ between tumor types. When classified into benign, borderline, and malignant tumors, the expression levels of these MMPs were different across the tumor subtypes. For example, MMP2 expression was higher in benign tumors than it was in borderline and malignant tumors, whereas MMP9 was higher in malignant tumors as compared to borderline tumors. In the stroma of serous tumors, the expression of MMP2 was highest in benign and borderline tumors as compared to malignant tumors. As for MMP9, it was highest in malignant tumors. In mucinous tumors, both MMP2 and MMP9 expression was highest in malignant tumors (Brun et al. 2008).

Although MMP2 staining was present in $76 \%$ of malignant tumors and $54 \%$ of benign tumors on immunohistochemical analysis, other studies have indicated that high levels of epithelial MMPs are not necessarily specific to malignant tumors. In fact, MMP2 is more frequently expressed in benign tumors than it is in carcinomas (Brun et al. 2012). These discrepancies may be a result of the different methods that the investigators used to analyze the samples as well as the arbitrary thresholds that were put in place by the different groups to determine staining intensity upon immunohistochemistry analysis (Brun et al. 2012).

Both MMP2 and MMP9 have been extensively studied in relation to their role in the migration and invasion of ovarian cancer. MMP2 and MMP9 have been shown to be secreted and activated in ovarian cancer, to be closely correlated with the invasion and metastasis of cancer cells, and to correlate with poor survival (Davidson et al. 1999).

When MMP9 was silenced using siRNA, the invasive ability of cancer cells decreased, which suggests a role for MMP9 in invasiveness (Hu et al. 2012). MMP9 has also been shown to be involved in the release of vascular endothelial growth factor from tumor cells and to cause ascites in ovarian cancer (Belotti et al. 2003). MMP9 was also suggested to play two potential roles in tumor development, where it acts as a tumor promoter when it is present in ovarian tumor stroma but prevents tumor advancement when it is expressed in the epithelium (Sillanpaa et al. 2007).

MMP2 has been previously shown to control the attachment and adhesion of metastatic ovarian cancer cells to peritoneal surfaces by cleaving ECM proteins and enhancing their binding to integrins (Kenny et al. 2008). Similarly, Kenny \& Lengyel (2009) showed that the presence of MMP2 in ovarian cancer regulates the ability of the ovarian cancer to metastasize. MMP2, like MMP7, was measured in the serum of ovarian cancer patients, and serum levels of MMP2 in those patients were lower than those of healthy controls (Acar et al. 2008).

Both MMP2 and MMP9 levels have been investigated in the urine of patients in combination with CA125. Coticchia et al. (2011) showed that MMP2 and MMP9 levels in the urine may be clinically helpful for diagnosing ovarian cancer, and their results were independent of CA125 levels. Platelet-derived growth factor-D (PDGF-D) has been also shown to promote ovarian cancer invasion, and this increase in invasion is caused by PDGF-D increasing the expression of MMP2 and MMP9 (Wang et al. 2011b). Finally, in a metaanalysis of 30 published studies on MMP9 and its prognostic use in ovarian cancer, the expression of MMP9 was shown to be generally positively correlated with poor prognosis (Li et al. 2013).

\section{The stromelysins: MMP3, MMP10, and MMP11}

MMP3 plays a significant role in regulating ECM remodeling as well as activating other MMPs. MMP3 is known to be overexpressed in cancerous hen ovaries as well as other human cancers (Choi et al. 2011). The activation of MMP3 in ovarian cancer has been linked to the down-regulation of miRNA200, wherein the induction of MMP3 overexpression caused a decrease in the ability of miR200 to inhibit ovarian cancer invasiveness. Similarly, an increase in the expression of miR200 has been shown to inhibit the expression of MMP3 (Sun et al. 2014). In humans, MMP3 expression is present in the cystic fluids of ovarian tumors and appears to be correlated with the activation of MMP7 and MMP9 (Furuya 1999). 
MMP10 is known to play a role in vascular remodeling (Rodriguez et al. 2008) and other functions, including cancer progression (Nabeshima et al. 2002), yet there have been very few studies on its role in ovarian cancer. Davidson et al. (2014) observed that when TP53 was mutated in ovarian cancer cell lines and exposed to hypoxic conditions, $40 \%$ (five genes) of the genes that were up-regulated were involved in ECM degradation, and one of them was MMP10. Our lab has shown that the activation of the PKC pathway in human ovarian cancer cell lines caused an increase in MMP10 expression, and this increase potentially plays a role in ovarian cancer migration (Al-Alem et al. 2013). In chemotherapeutic treatment, MMP10 was highly induced in ovarian cancer cells that became resistant to platinum-based chemotherapy as compared to cells that were non-resistant (Solar \& Sytkowski 2011). Furthermore, MMP3 and MMP10 expression was increased in rat ovarian surface epithelia following Ras activation (Ulku et al. 2003).

MMP11 is known to be involved in tumor remodeling; however, a study that explored the protein expression of MMP2 and MMP11 in 100 tissue samples from patients with stage III ovarian cancer showed that MMP2, but not MMP11, was correlated with aggressive cancer cells (Perigny et al. 2008). In contrast, Mueller et al. (2000) showed that there was a higher percentage of low malignant tumors that express MMP11 in the stroma that is adjacent to the tumor. This expression correlated positively with tumor stage.

\section{The membrane type MMPs: MMP14-17, MMP24, and MMP25}

The membrane type MMPs are unique among the MMP family because they are not secreted into the extracellular space; rather, they contain a domain that anchors them into or onto the plasma membrane (Fig. 2). An extracellular domain directs the proteolytic component of the enzyme to the exterior surface of the cell. There are six members of this family, and they are divided into type I and type II MT-MMPs (Sounni \& Noel 2005). The type I MT-MMPs include MT1 (MMP14), MT2 (MMP15), MT3 (MMP16), and MT5 (MMP24), and they have a transmembrane domain and an intracytoplasmic domain. The type II MT-MMPs, MT4 (MMP17) and MT6 (MMP25), have a glycosylphosphatidylinositol (GPI) link domain that anchors them onto the cell membrane (Curry \& Osteen 2003, Sounni \& Noel 2005). By virtue of their presence on the surface of the cell, all of the MT-MMPs are thought to participate in pericellular proteolysis to promote cell growth and migration, which are hallmarks of cancer metastasis (Murphy et al. 1999). For example, high local concentrations of active MT1 on the cell membrane of metastatic cancer cells have been proposed to play an important role in cell migration (Sabeh et al. 2004, Wolf et al. 2007, Kessenbrock et al.
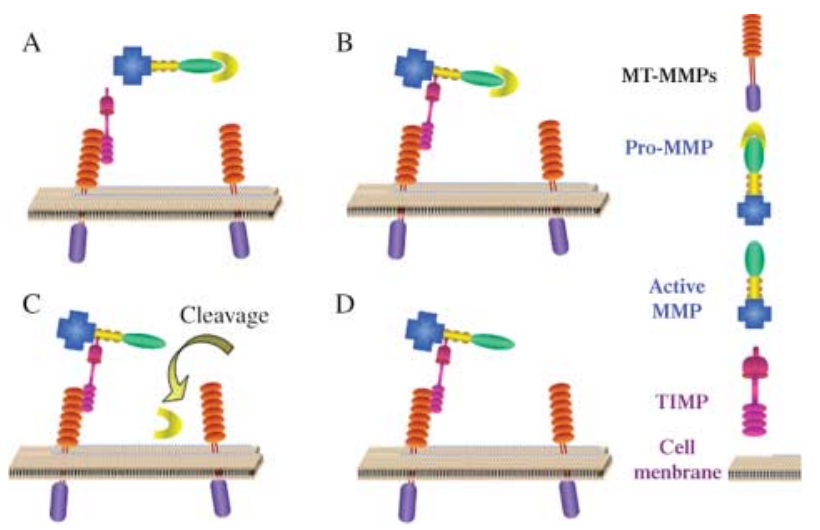

Figure 2 MMPactivation. Certain MMPs are activated by the membrane type MMPs. (A) TIMPs attach to the active site of the MT-MMPs. This allows MMPs surrounding the cell in proximity to the MT-MMPs to be bound by TIMPs, thereby forming a MT-MMP:TIMP:ProMMP complex. (B) The complex is in close proximity to other MT-MMPs on the cell surface, which are capable of cleaving the pro-peptide $(C)$ and cause the MMP to become active (D).

2010). MMPs are mostly activated via serine proteinases that cleave pro-domain peptide bonds. In addition, MT-MMPs can cleave pro-forms of other enzymes, including secreted pro-MMPs such as MMP2 and MMP9, as discussed in the earlier section on the gelatinases, which contributes to their involvement in ovarian cancer. MMP14 in particular activates MMP2, whereas MMP15 and MMP24 fail to activate MMP2 (Zucker et al. 1998, Miyamori et al. 2000). MT-MMPs are inhibited via TIMP2, whose C-terminal acts as a receptor for the pro-MMP2. A nearby uninhibited MT-MMP cleaves the adjacent pro-MMP2, which is further cleaved to the active form of MMP2 (Strongin et al. 1995, Deryugina et al. 2001) (Fig. 2).

An association has been described between ovarian cancer and the MT-MMPs. For example, MT1 and MT2 have been reported to be associated with ovarian carcinoma (Fishman et al. 1996, Stack et al. 1998). MT1 has been associated with aggressive tumor behavior (Drew et al. 2004) and a shorter disease-specific survival in epithelial ovarian cancer (Kamat et al. 2006). In contrast to MT1 and MT2, MT3 mRNA was not detected in malignant pleural or peritoneal effusions (Davidson et al. 2001).

There are extremely limited reports on the association of MT4, MT5, and MT6 with ovarian cancer. In the normal ovary, we have observed an increase in MT6 around the time of ovulation (Puttabyatappa et al. 2014). In ovarian cancer, the data that do exist have been performed in cell lines. For example, Delassus et al. (2010) reported that MMP25, along with other MMPs, was differentially regulated in SKOv3 ovarian cells. However, in their provocative study, these investigators reported striking variability in MMP expression in cancer cell lines. A comparison of the MMP signaling pathways 
in the ovarian cancer SKOV3 cells with those from lung, brain, prostate, or breast cancer cells revealed that the induction of MMP expression differed so widely that almost $90 \%$ of the pathways were different in cells from one cancer to another (Delassus et al. 2010). In 18 out of 51 signaling pathways, a known suppressor of cancer progression stimulated, rather than inhibited, MMP expression. Likewise, ten signaling pathways that upregulated MMP expression in the cells of some cancers resulted in the down-regulation of MMP in other cancer cells. These results highlight that there are pronounced differences in the signaling pathways between cells from different cancers (Delassus et al. 2010).

Support for the role of the MT-MMPs in ovarian cancer invasion is forthcoming from cell culture studies. OVCA 433 cells, which express a mutated form of MT1 that resulted in sustained cell surface activity by MT1, caused a cellular phenotypic epithelial-mesenchymal transition characterized by enhanced migration and collagen invasion (Moss et al. 2009). Likewise, MT1 increased the invasion of ovarian carcinoma cells through the activation of pro-MMP2 (Fishman et al. 1996).

In addition to their role in invasion, the MT-MMPs may play a key role in the vascular changes or vasculogenic mimicry associated with ovarian tumor formation and growth. MT1 is known to activate the pro-form of MMP2 to the active enzyme (Sood et al. 2004). Together, MMP2 and MMP14 appear to regulate the development of vasculogenic-like networks and matrix remodeling by aggressive ovarian cancer cells (Sood et al. 2004), which may allow further cell growth and proliferation (Fig. 3).

\section{The matrilysins: MMP7 and MMP26}

MMP7, also known as matrilysin-1, is the smallest member of the MMP family and acts on a variety of substrates (Wang et al. 2005). It is also one of the few MMPs that is secreted by tumor cells rather than stromal cells, and it has been shown to be expressed in almost all organ tumors in the body (Wielockx et al. 2004, li et al. 2006). MMP7 overexpression has been implicated in numerous cancers and is linked to advanced cancer stages and poor prognosis (li et al. 2006). In particular, MMP7 has been shown to be elevated in $80 \%$ of malignant human ovarian cancers as compared to $40 \%$ in normal or benign samples. MMP7 has also been shown to be expressed in stromal ovarian cancer tissues, particularly those of serous cancers (Brun et al. 2008). Polymorphisms in the MMP7 promoter region have shown that single nucleotide polymorphisms in MMP7 are significantly higher in ovarian cancer patients than they are in controls (Li et al. 2006). In addition, the serum levels of MMP7 were higher in patients with ovarian serous (Meinhold-Heerlein et al. 2007) and mucinous (Shigemasa et al. 2000) cancers as compared to controls. MMP7 serum levels were also higher in preoperative as compared to post-operative patients (Tanimoto et al.
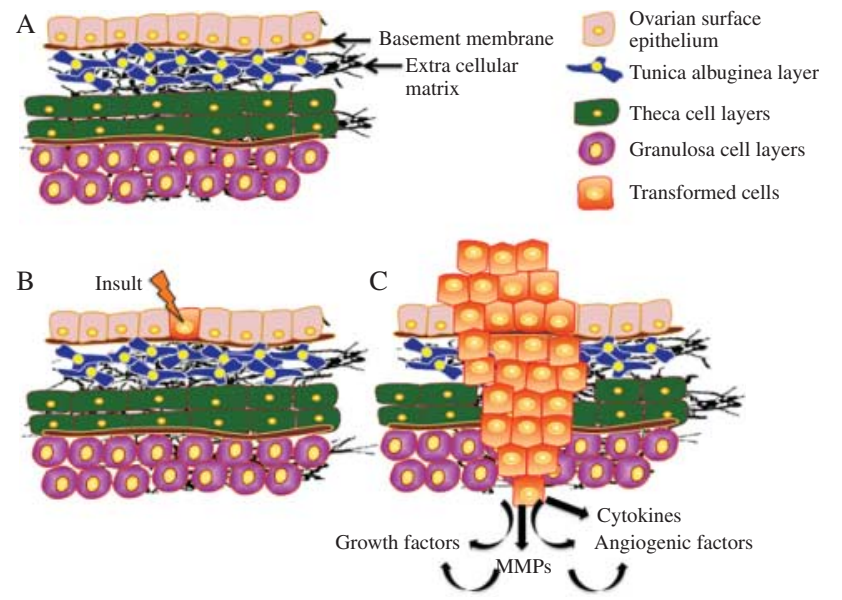

Figure 3 Schematic of ovarian cancer formation. The ovary is comprised of several cell layers, including the surface epithelium and the underlying tunica aluginea, which are separated from each other by a basement membrane. The theca layer lies under the tunica albuginea and is separated from the granulosa cell layer by a basement membrane (A). The presence of an insult or a spontaneous mutation to the cells of the surface epithelium causes cells to transform (B). This transformation leads to an uncontrolled growth of cells and the increased expression of growth factors, immune factors, MMPs, and others. More importantly, for continuous cell growth, cells need to degrade the surrounding matrices; hence, ovarian cancer cells utilize an increased expression of specific MMPs to destroy the type of matrix adjacent to the tumor cells $(\mathrm{C})$.

1999) and were also higher before chemotherapy (Gershtein et al. 2010), which indicates that MMP7 may be useful as a biomarker. In contrast, Sillanpaa et al. (2006) showed that the 10-year disease-related survival was better when the tumor expression of MMP7 cells was elevated.

MMP7 secretion has been shown to correlate with metastasis (Shiomi \& Okada 2003, Wang et al. 2005). One potential mechanism for the increased invasiveness seen with MMP7 is its activation of MMP2 and MMP9 (li et al. 2006). MMP2 has been previously shown to control the attachment and adhesion of metastatic ovarian cancer cells to peritoneal surfaces by cleaving ECM proteins and enhancing their binding to integrins (Kenny et al. 2008). Another mechanism for MMP7 action is the degradation of IGFBP, which thus increases the bioavailability of IGF and increases the growth of cancer cells (li et al. 2006).

Very few reports have examined MMP26 (matrilysin2) expression in ovarian cancer. MMP26 was not detected in ovarian cancer cell lines, such as BG-1 and OAW-42 (Schropfer et al. 2010), nor was it significantly elevated in tissues from ovarian cancer patients (Zhao et al. 2009). In contrast, Ripley et al. (2006) reported that immunostaining of MMP26 was increased with ovarian carcinoma tumor stage III/IV, which indicates that the invading tumor cells possess the strongest staining for MMP26. 


\section{The metalloelastase: MMP12}

MMP12 shares homology with the other MMPs in that it has a similar domain structure with both the collagenases and stromelysins 1 and 2 . However, MMP12 is distinct from the other MMPs insofar as it only shares a $33-48 \%$ amino acid homology with the other members of this family (Shapiro et al. 1993). MMP12 is produced by macrophages, degrades elastin, and has been shown to be associated with inflammatory skin diseases, atherosclerosis, angiogenesis, and cancer (Nenan et al. 2005, Chen et al. 2013). Very few studies have explored the role of MMP12 in ovarian cancer. Polymorphism studies indicate that an $82 \mathrm{~A} / \mathrm{G}$ polymorphism of MMP12 may be a risk factor for the development of epithelial ovarian cancer progression (Li et al. 2009).

\section{Conclusion}

There is an extensive body of literature to suggest that MMP overexpression is associated with an increased metastatic potential of ovarian tumors, which leads to poor prognosis and decreased survival. However, as the present review highlights, the expression pattern of each individual MMP varies depending on the type of tumor, tumor stage, patient diagnosis, means of MMP identification (such as PCR), enzyme activity or immunohistochemistry, and even potentially the patient population. This variability is highlighted by studies that have examined the overexpression of MMPs related to polymorphisms in the respective MMP promoter or the differences in MMP expression in different cancer cell lines. Variability in the ability to detect MMP expression and activity may obfuscate any conclusions regarding any one MMP in the initiation, progression, metastasis, and invasion of a specific tumor.

Additionally, emerging evidence suggests that MMPs may have non-proteolytic actions working through the hemopexin domain (Correia et al. 2013). With sensitive advances in technology, such as RNAseq, proteomics, and 3D modeling, a more concise picture of the involvement of the MMP family in the development and progression of ovarian cancer should emerge. This will allow for the development of small-molecule MMP inhibitors that block both the proteolytic and nonproteolytic actions of the MMPs that could be used as an adjuvant therapy in conjunction with existing therapies to combat ovarian cancer.

\section{Declaration of interest}

The authors declare that there is no conflict of interest that could be perceived as prejudicing the impartiality of the review.

\section{Funding}

This work was supported by the National Institutes of Health (grant numbers HD057446, R03HD071291, P01HD071875, and UL1TR000117).

\section{References}

Acar A, Onan A, Coskun U, Uner A, Bagriacik U, Atalay F, Unsal DK \& Guner H 2008 Clinical significance of serum MMP-2 and MMP-7 in patients with ovarian cancer. Medical Oncology 25 279-283. (doi:10. 1007/s12032-007-9031-1)

Agarwal A, Covic L, Sevigny LM, Kaneider NC, Lazarides K, Azabdaftari G, Sharifi S \& Kuliopulos A 2008 Targeting a metalloprotease-PAR1 signaling system with cell-penetrating pepducins inhibits angiogenesis, ascites, and progression of ovarian cancer. Molecular Cancer Therapeutics 7 2746-2757. (doi:10.1158/1535-7163.MCT-08-0177)

Agarwal A, Tressel SL, Kaimal R, Balla M, Lam FH, Covic L \& Kuliopulos A 2010 Identification of a metalloprotease-chemokine signaling system in the ovarian cancer microenvironment: implications for antiangiogenic therapy. Cancer Research 70 5880-5890. (doi:10.1158/0008-5472. CAN-09-4341)

Al-Alem LF, McCord LA, Southard RC, Kilgore MW \& Curry TE Jr 2013 Activation of the PKC pathway stimulates ovarian cancer cell proliferation, migration, and expression of MMP7 and MMP10. Biology of Reproduction 89 73. (doi:10.1095/biolreprod.112.102327)

Arechavaleta-Velasco F, Cuevas-Antonio R, Dominguez-Lopez P, EstradaMoscoso I, Imani-Razavi FS, Zeferino-Toquero M \& Diaz-Cueto L 2014 Matrix metalloproteinase-8 promoter gene polymorphisms in Mexican women with ovarian cancer. Medical Oncology 31 132. (doi:10.1007/ s12032-014-0132-3)

Behrens P, Rothe M, Florin A, Wellmann A \& Wernert N 2001 Invasive properties of serous human epithelial ovarian tumors are related to Ets-1, MMP-1 and MMP-9 expression. International Journal of Molecular Medicine 8 149-154. (doi:10.3892/ijmm.8.2.149)

Belotti D, Paganoni P, Manenti L, Garofalo A, Marchini S, Taraboletti G \& Giavazzi R 2003 Matrix metalloproteinases (MMP9 and MMP2) induce the release of vascular endothelial growth factor (VEGF) by ovarian carcinoma cells: implications for ascites formation. Cancer Research 63 5224-5229.

Berchuck A, Iversen ES, Luo J, Clarke JP, Horne H, Levine DA, Boyd J, Alonso MA, Secord AA, Bernardini MQ et al. 2009 Microarray analysis of early stage serous ovarian cancers shows profiles predictive of favorable outcome. Clinical Cancer Research 15 2448-2455. (doi:10.1158/1078-0432.CCR-08-2430)

Birkedal-Hansen H, Moore WG, Bodden MK, Windsor LJ, BirkedalHansen B, DeCarlo A \& Engler JA 1993 Matrix metalloproteinases: a review. Critical Reviews in Oral Biology and Medicine 4 197-250. (doi:10.1177/10454411930040020401)

Boire A, Covic L, Agarwal A, Jacques S, Sherifi S \& Kuliopulos A 2005 PAR1 is a matrix metalloprotease- 1 receptor that promotes invasion and tumorigenesis of breast cancer cells. Cell 120 303-313. (doi:10.1016/j. cell.2004.12.018)

Borkakoti N 2000 Structural studies of matrix metalloproteinases. Journal of Molecular Medicine 78 261-268. (doi:10.1007/s001090000113)

Brun JL, Cortez A, Commo F, Uzan S, Rouzier R \& Darai E 2008 Serous and mucinous ovarian tumors express different profiles of MMP-2, -7, -9, MT1-MMP, and TIMP-1 and -2. International Journal of Oncology 33 1239-1246. (doi:10.3892/ijo_00000114)

Brun JL, Cortez A, Lesieur B, Uzan S, Rouzier R \& Darai E 2012 Expression of MMP-2, -7, -9, MT1-MMP and TIMP-1 and -2 has no prognostic relevance in patients with advanced epithelial ovarian cancer. Oncology Reports 27 1049-1057. (doi:10.3892/or.2011.1608)

Chen Q, Jin M, Yang F, Zhu J, Xiao Q \& Zhang L 2013 Matrix metalloproteinases: inflammatory regulators of cell behaviors in vascular formation and remodeling. Mediators of Inflammation 2013928315. (doi:10.1155/2013/928315)

Choi JH, Wong AS, Huang HF \& Leung PC 2007 Gonadotropins and ovarian cancer. Endocrine Reviews 28 440-461. (doi:10.1210/er.2006-0036)

Choi JW, Ahn SE, Rengaraj D, Seo HW, Lim W, Song G \& Han JY 2011 Matrix metalloproteinase 3 is a stromal marker for chicken ovarian cancer. Oncology Letters 2 1047-1051. (doi:10.3892/ol.2011.391)

Collaborative Group on Epidemiological Studies of Ovarian Cancer, Beral V, Doll R, Hermon C, Peto R \& Reeves G 2008 Ovarian cancer and oral contraceptives: collaborative reanalysis of data from 45 epidemiological studies including 23,257 women with ovarian cancer and 87,303 controls. Lancet 371 303-314. (doi:10.1016/S0140-6736(08)60167-1) 
Correia AL, Mori H, Chen El, Schmitt FC \& Bissell MJ 2013 The hemopexin domain of MMP3 is responsible for mammary epithelial invasion and morphogenesis through extracellular interaction with HSP90ß. Genes and Development 27 805-817. (doi:10.1101/gad.211383.112)

Coticchia CM, Curatolo AS, Zurakowski D, Yang J, Daniels KE, Matulonis UA \& Moses MA 2011 Urinary MMP-2 and MMP-9 predict the presence of ovarian cancer in women with normal CA125 levels. Gynecologic Oncology 123 295-300. (doi:10.1016/j.ygyno. 2011.07.034)

Crum CP, Drapkin R, Miron A, Ince TA, Muto M, Kindelberger DW \& Lee Y 2007a The distal fallopian tube: a new model for pelvic serous carcinogenesis. Current Opinion in Obstetrics \& Gynecology 19 3-9. (doi:10.1097/GCO.0b013e328011a21f)

Crum CP, Drapkin R, Kindelberger D, Medeiros F, Miron A \& Lee Y $2007 b$ Lessons from BRCA: the tubal fimbria emerges as an origin for pelvic serous cancer. Clinical Medicine \& Research 5 35-44. (doi:10.3121/cmr. 2007.702)

Curry TE Jr \& Osteen KG 2003 The matrix metalloproteinase system: changes, regulation, and impact throughout the ovarian and uterine reproductive cycle. Endocrine Reviews 24 428-465. (doi:10.1210/er. 2002-0005)

Davidson B, Goldberg I, Gotlieb WH, Kopolovic J, Ben-Baruch G, Nesland JM, Berner A, Bryne M \& Reich R 1999 High levels of MMP2, MMP-9, MT1-MMP and TIMP-2 mRNA correlate with poor survival in ovarian carcinoma. Clinical \& Experimental Metastasis 17 799-808. (doi:10.1023/A:1006723011835)

Davidson B, Goldberg I, Berner A, Nesland JM, Givant-Horwitz V, Bryne M, Risberg B, Kristensen GB, Trope CG, Kopolovic J et al. 2001 Expression of membrane-type 1,2, and 3 matrix metalloproteinases messenger RNA in ovarian carcinoma cells in serous effusions. American Journal of Clinical Pathology 115 517-524. (doi:10.1309/B1YX-L8DBTGY1-7905)

Davidson BA, Rubatt JM, Corcoran DL, Teoh DK, Bernardini MQ, Grace LA, Soper WJ, Berchuck A, Siamakpour-Reihani S, Chen W et al. 2014 Differential angiogenic gene expression in TP53 wild-type and mutant ovarian cancer cell lines. Frontiers in Oncology 4163. (doi:10.3389/fonc.2014.00163)

Delassus GS, Cho H, Hoang S \& Eliceiri GL 2010 Many new down- and up-regulatory signaling pathways, from known cancer progression suppressors to matrix metalloproteinases, differ widely in cells of various cancers. Journal of Cellular Physiology 224 549-558. (doi:10.1002/jcp. 22157)

Deryugina El, Ratnikov B, Monosov E, Postnova TI, DiScipio R, Smith JW \& Strongin AY 2001 MT1-MMP initiates activation of pro-MMP-2 and integrin $\alpha v \beta 3$ promotes maturation of MMP-2 in breast carcinoma cells. Experimental Cell Research 263 209-223. (doi:10.1006/excr.2000. 5118)

Dor J, Lerner-Geva L, Rabinovici J, Chetrit A, Levran D, Lunenfeld B, Mashiach S \& Modan B 2002 Cancer incidence in a cohort of infertile women who underwent in vitro fertilization. Fertility and Sterility $\mathbf{7 7}$ 324-327. (doi:10.1016/S0015-0282(01)02986-7)

Drew AF, Blick TJ, Lafleur MA, Tim EL, Robbie MJ, Rice GE, Quinn MA \& Thompson EW 2004 Correlation of tumor- and stromal-derived MT1MMP expression with progression of human ovarian tumors in SCID mice. Gynecologic Oncology 95 437-448. (doi:10.1016/j.ygyno.2004.08.032)

Fathalla MF 1971 Incessant ovulation - a factor in ovarian neoplasia? Lancet 2 163. (doi:10.1016/S0140-6736(71)92335-X)

Fathalla MF 2013 Incessant ovulation and ovarian cancer - a hypothesis re-visited. Facts, Views \& Vision in ObGyn 5 292-297.

Fishman DA, Bafetti LM \& Stack MS 1996 Membrane-type matrix metalloproteinase expression and matrix metalloproteinase-2 activation in primary human ovarian epithelial carcinoma cells. Invasion \& Metastasis 16 150-159.

Furuya M 1999 Analysis of matrix metalloproteinases and related tissue inhibitors in cystic fluids of ovarian tumors. Hokkaido Igaku Zasshi $\mathbf{7 4}$ 145-155.

Gershtein ES, Levkina NV, Digayeva MA, Laktionov KP, Tereshkina IV \& Kushlinsky NE 2010 Matrix metalloproteinases 2, 7, and 9 and tissue inhibitor of metalloproteinases-1 in tumors and serum of patients with ovarian neoplasms. Bulletin of Experimental Biology and Medicine 149 628-631. (doi:10.1007/s10517-010-1010-4)
Gomez DE, Alonso DF, Yoshiji H \& Thorgeirsson UP 1997 Tissue inhibitors of metalloproteinases: structure, regulation and biological functions. European Journal of Cell Biology 74 111-122.

Hantke B, Harbeck N, Schmalfeldt B, Claes I, Hiller O, Luther MO, Welk A, Kuhn W, Schmitt M, Tschesche H et al. 2003 Clinical relevance of matrix metalloproteinase-13 determined with a new highly specific and sensitive ELISA in ascitic fluid of advanced ovarian carcinoma patients. Biological Chemistry 384 1247-1251. (doi:10. 1515/BC.2003.137)

Hu X, Li D, Zhang W, Zhou J, Tang B \& Li L 2012 Matrix metalloproteinase9 expression correlates with prognosis and involved in ovarian cancer cell invasion. Archives of Gynecology and Obstetrics 286 1537-1543. (doi:10.1007/s00404-012-2456-6)

li M, Yamamoto H, Adachi Y, Maruyama Y \& Shinomura Y 2006 Role of matrix metalloproteinase-7 (matrilysin) in human cancer invasion, apoptosis, growth, and angiogenesis. Experimental Biology and Medicine $23120-27$.

John A \& Tuszynski G 2001 The role of matrix metalloproteinases in tumor angiogenesis and tumor metastasis. Pathology Oncology Research 7 14-23. (doi:10.1007/BF03032599)

Kamat AA, Fletcher M, Gruman LM, Mueller P, Lopez A, Landen CN Jr, Han L, Gershenson DM \& Sood AK 2006 The clinical relevance of stromal matrix metalloproteinase expression in ovarian cancer. Clinical Cancer Research 12 1707-1714. (doi:10.1158/1078-0432.CCR-05-2338)

Kanamori Y, Matsushima M, Minaguchi T, Kobayashi K, Sagae S, Kudo R, Terakawa N \& Nakamura Y 1999 Correlation between expression of the matrix metalloproteinase-1 gene in ovarian cancers and an insertion/deletion polymorphism in its promoter region. Cancer Research $594225-4227$.

Karabulut S, Aksit E, Tas F, Ciftci R, Aydiner A, Yildiz I, Keskin S, Eralp Y, Yasasever CT, Vatansever S et al. 2014 Is there any diagnostic value of serum protease-activated receptor-1 (PAR1) levels on determination of epithelial ovarian carcinoma? Tumour Biology 35 4323-4329. (doi:10.1007/s13277-013-1567-4)

Kenny HA \& Lengyel E 2009 MMP-2 functions as an early response protein in ovarian cancer metastasis. Cell Cycle 8 683-688. (doi:10.4161/cc.8. 5.7703)

Kenny HA, Kaur S, Coussens LM \& Lengyel E 2008 The initial steps of ovarian cancer cell metastasis are mediated by MMP-2 cleavage of vitronectin and fibronectin. Journal of Clinical Investigation 118 1367-1379. (doi:10.1172/JCI33775)

Kessenbrock K, Plaks V \& Werb Z 2010 Matrix metalloproteinases: regulators of the tumor microenvironment. Cell 141 52-67. (doi:10. 1016/j.cell.2010.03.015)

Kleiner DE Jr \& Stetler-Stevenson WG 1993 Structural biochemistry and activation of matrix metalloproteases. Current Opinion in Cell Biology $\mathbf{5}$ 891-897. (doi:10.1016/0955-0674(93)90040-W)

Koshiyama M, Matsumura N \& Konishi I 2014 Recent concepts of ovarian carcinogenesis: type I and type II. BioMed Research International 2014 934261. (doi:10.1155/2014/934261)

Li Y, Jin X, Kang S, Wang Y, Du H, Zhang J, Guo W, Wang N \& Fang S 2006 Polymorphisms in the promoter regions of the matrix metalloproteinases-1, $-3,-7$, and -9 and the risk of epithelial ovarian cancer in China. Gynecologic Oncology 101 92-96. (doi:10.1016/j.ygyno.2005. 09.058)

Li Y, Jia JH, Kang S, Zhang XJ, Zhao J, Wang N, Zhou RM, Sun DL, Duan YN \& Wang DJ 2009 The functional polymorphisms on promoter region of matrix metalloproteinase-12, -13 genes may alter the risk of epithelial ovarian carcinoma in Chinese. International Journal of Gynecological Cancer 19 129-133. (doi:10.1111/IGC.0b013e31819a1d8e)

Li LN, Zhou X, Gu Y \& Yan J 2013 Prognostic value of MMP-9 in ovarian cancer: a meta-analysis. Asian Pacific Journal of Cancer Prevention 14 4107-4113. (doi:10.7314/APJCP.2013.14.7.4107)

Massague J 2008 TGF $\beta$ in cancer. Cell 134 215-230. (doi:10.1016/j.cell. 2008.07.001)

Meinhold-Heerlein I, Bauerschlag D, Zhou Y, Sapinoso LM, Ching K, Frierson H Jr, Brautigam K, Sehouli J, Stickeler E, Konsgen D et al. 2007 An integrated clinical-genomics approach identifies a candidate multianalyte blood test for serous ovarian carcinoma. Clinical Cancer Research 13 458-466. (doi:10.1158/1078-0432.CCR-06-0691)

Miyamori H, Hasegawa K, Kim KR \& Sato H 2000 Expression of metastasisassociated mts1 gene is co-induced with membrane type-1 matrix 
metalloproteinase (MT1-MMP) during oncogenic transformation and tubular formation of Madin Darby canine kidney (MDCK) epithelial cells. Clinical \& Experimental Metastasis 18 51-56. (doi:10.1023/ A:1026523418456)

Moss NM, Wu YI, Liu Y, Munshi HG \& Stack MS 2009 Modulation of the membrane type 1 matrix metalloproteinase cytoplasmic tail enhances tumor cell invasion and proliferation in three-dimensional collagen matrices. Journal of Biological Chemistry 284 19791-19799. (doi:10. 1074/jbc.M109.020362)

Mu D, Cambier S, Fjellbirkeland L, Baron JL, Munger JS, Kawakatsu H, Sheppard D, Broaddus VC \& Nishimura SL 2002 The integrin $\alpha(\mathrm{v}) \beta 8$ mediates epithelial homeostasis through MT1-MMP-dependent activation of TGF- $\beta 1$. Journal of Cell Biology 157 493-507. (doi:10.1083/ jcb.200109100)

Mueller J, Brebeck B, Schmalfeldt B, Kuhn W, Graeff H \& Hofler H 2000 Stromelysin-3 expression in invasive ovarian carcinomas and tumours of low malignant potential. Virchows Archiv 437 618-624. (doi:10.1007/ s004280000261)

Murphy G, Knauper V, Cowell S, Hembry R, Stanton H, Butler G, Freije J, Pendas AM \& Lopez-Otin C 1999 Evaluation of some newer matrix metalloproteinases. Annals of the New York Academy of Sciences $\mathbf{8 7 8}$ 25-39. (doi:10.1111/j.1749-6632.1999.tb07672.x)

Nabeshima K, Inoue T, Shimao Y \& Sameshima T 2002 Matrix metalloproteinases in tumor invasion: role for cell migration. Pathology International 52 255-264. (doi:10.1046/j.1440-1827.2002.01343.x)

Nagase H \& Woessner JF Jr 1999 Matrix metalloproteinases. Journal of Biological Chemistry 274 21491-21494. (doi:10.1074/jbc.274.31. 21491)

Nenan S, Boichot E, Lagente V \& Bertrand CP 2005 Macrophage elastase (MMP-12): a pro-inflammatory mediator? Memórias do Instituto Oswaldo Cruz 100 (Suppl 1) 167-172. (doi:10.1590/S007402762005000900028)

Perigny M, Bairati I, Harvey I, Beauchemin M, Harel F, Plante M \& Tetu B 2008 Role of immunohistochemical overexpression of matrix metalloproteinases MMP-2 and MMP-11 in the prognosis of death by ovarian cancer. American Journal of Clinical Pathology 129 226-231. (doi:10. 1309/49LA9XCBGWJ8F2KM)

Puttabyatappa M, Jacot TA, Al-Alem LF, Rosewell KL, Duffy DM, Brannstrom M \& Curry TE Jr 2014 Ovarian membrane-type matrix metalloproteinases: induction of MMP14 and MMP16 during the periovulatory period in the rat, macaque, and human. Biology of Reproduction 91 34. (doi:10.1095/biolreprod.113.115717)

Ripley D, Tunuguntla R, Susi L \& Chegini N 2006 Expression of matrix metalloproteinase- 26 and tissue inhibitors of metalloproteinase- 3 and -4 in normal ovary and ovarian carcinoma. International Journal of Gynecological Cancer 16 1794-1800. (doi:10.1111/j.1525-1438.2006. 00714.x)

Rodriguez JA, Orbe J, Martinez de Lizarrondo S, Calvayrac $O$, Rodriguez C, Martinez-Gonzalez J \& Paramo JA 2008 Metalloproteinases and atherothrombosis: MMP-10 mediates vascular remodeling promoted by inflammatory stimuli. Frontiers in Bioscience $\mathbf{1 3}$ 2916-2921. (doi:10.2741/2896)

Rossing MA, Daling JR, Weiss NS, Moore DE \& Self SG 1994 Ovarian tumors in a cohort of infertile women. New England Journal of Medicine 331 771-776. (doi:10.1056/NEJM199409223311204)

Sabeh F, Ota I, Holmbeck K, Birkedal-Hansen H, Soloway P, Balbin M, Lopez-Otin C, Shapiro S, Inada M, Krane S et al. 2004 Tumor cell traffic through the extracellular matrix is controlled by the membrane-anchored collagenase MT1-MMP. Journal of Cell Biology 167 769-781. (doi:10. 1083/jcb.200408028)

Schropfer A, Kammerer U, Kapp M, Dietl J, Feix S \& Anacker J 2010 Expression pattern of matrix metalloproteinases in human gynecological cancer cell lines. BMC Cancer 10 553. (doi:10.1186/1471-240710-553)

Shapiro SD, Kobayashi DK \& Ley TJ 1993 Cloning and characterization of a unique elastolytic metalloproteinase produced by human alveolar macrophages. Journal of Biological Chemistry 268 23824-23829.

Shigemasa K, Tanimoto H, Sakata K, Nagai N, Parmley TH, Ohama K \& O'Brien TJ 2000 Induction of matrix metalloprotease-7 is common in mucinous ovarian tumors including early stage disease. Medical Oncology 17 52-58. (doi:10.1007/BF02826217)
Shiomi T \& Okada Y 2003 MT1-MMP and MMP-7 in invasion and metastasis of human cancers. Cancer Metastasis Reviews 22 145-152. (doi:10.1023/A:1023039230052)

Sillanpaa SM, Anttila MA, Voutilainen KA, Ropponen KM, Sironen RK, Saarikoski SV \& Kosma VM 2006 Prognostic significance of matrix metalloproteinase-7 in epithelial ovarian cancer and its relation to $\beta$-catenin expression. International Journal of Cancer 119 1792-1799. (doi:10.1002/ijc.22067)

Sillanpaa S, Anttila M, Voutilainen K, Ropponen K, TurpeenniemiHujanen T, Puistola U, Tammi R, Tammi M, Sironen R, Saarikoski S et al. 2007 Prognostic significance of matrix metalloproteinase-9 (MMP9) in epithelial ovarian cancer. Gynecologic Oncology 104 296-303. (doi:10.1016/j.ygyno.2006.09.004)

Solar P \& Sytkowski AJ 2011 Differentially expressed genes associated with cisplatin resistance in human ovarian adenocarcinoma cell line A2780. Cancer Letters 309 11-18. (doi:10.1016/j.canlet.2011.05.008)

Sood AK, Fletcher MS, Coffin JE, Yang M, Seftor EA, Gruman LM, Gershenson DM \& Hendrix MJ 2004 Functional role of matrix metalloproteinases in ovarian tumor cell plasticity. American Journal of Obstetrics and Gynecology 190 899-909. (doi:10.1016/ j.ajog.2004.02.011)

Sounni NE \& Noel A 2005 Membrane type-matrix metalloproteinases and tumor progression. Biochimie 87 329-342. (doi:10.1016/j.biochi.2004. 07.012)

Stack MS, Ellerbroek SM \& Fishman DA 1998 The role of proteolytic enzymes in the pathology of epithelial ovarian carcinoma. International Journal of Oncology 12 569-576. (doi:10.3892/ijo.12.3.569)

Stadlmann S, Pollheimer J, Moser PL, Raggi A, Amberger A, Margreiter R, Offner FA, Mikuz G, Dirnhofer S \& Moch H 2003 Cytokine-regulated expression of collagenase-2 (MMP-8) is involved in the progression of ovarian cancer. European Journal of Cancer 39 2499-2505. (doi:10.1016/j.ejca.2003.08.011)

Sternlicht MD \& Werb Z 2001 How matrix metalloproteinases regulate cell behavior. Annual Review of Cell and Developmental Biology 17 463-516. (doi:10.1146/annurev.cellbio.17.1.463)

Strongin AY, Collier I, Bannikov G, Marmer BL, Grant GA \& Goldberg GI 1995 Mechanism of cell surface activation of 72-kDa type IV collagenase. Isolation of the activated form of the membrane metalloprotease. Journal of Biological Chemistry 270 5331-5338. (doi:10.1074/jbc.270.10.5331)

Sun N, Zhang Q, Xu C, Zhao Q, Ma Y, Lu X, Wang L \& Li W 2014 Molecular regulation of ovarian cancer cell invasion. Tumour Biology $\mathbf{3 5}$ 11359-11366. (doi:10.1007/s13277-014-2434-7)

Tanimoto H, Underwood LJ, Shigemasa K, Parmley TH, Wang Y, Yan Y, Clarke J \& O'Brien TJ 1999 The matrix metalloprotease pump-1 (MMP-7, Matrilysin): a candidate marker/target for ovarian cancer detection and treatment. Tumour Biology 20 88-98. (doi:10.1159/ 000030051)

Tingulstad S, Skjeldestad FE, Halvorsen TB \& Hagen B 2003 Survival and prognostic factors in patients with ovarian cancer. Obstetrics and Gynecology 101 885-891. (doi:10.1016/S0029-7844(03)00123-6)

Ulku AS, Schafer R \& Der CJ 2003 Essential role of Raf in Ras transformation and deregulation of matrix metalloproteinase expression in ovarian epithelial cells. Molecular Cancer Research $\mathbf{1}$ 1077-1088.

Venn A, Watson L, Bruinsma F, Giles G \& Healy D 1999 Risk of cancer after use of fertility drugs with in-vitro fertilisation. Lancet 354 1586-1590. (doi:10.1016/S0140-6736(99)05203-4)

Wang FQ, So J, Reierstad S \& Fishman DA 2005 Matrilysin (MMP-7) promotes invasion of ovarian cancer cells by activation of progelatinase. International Journal of Cancer 114 19-31. (doi:10.1002/ijc.20697)

Wang FQ, Fisher J \& Fishman DA 2011 a MMP-1-PAR1 axis mediates LPAinduced epithelial ovarian cancer (EOC) invasion. Gynecologic Oncology 120 247-255. (doi:10.1016/j.ygyno.2010.10.032)

Wang Y, Hu C, Dong R, Huang X \& Qiu H 2011 b Platelet-derived growth factor-D promotes ovarian cancer invasion by regulating matrix metalloproteinases 2 and 9. Asian Pacific Journal of Cancer Prevention 12 3367-3370.

Wenham RM, Calingaert B, Ali S, McClean K, Whitaker R, Bentley R, Lancaster JM, Schildkraut J, Marks J \& Berchuck A 2003 Matrix 
metalloproteinase- 1 gene promoter polymorphism and risk of ovarian cancer. Journal of the Society for Gynecologic Investigation 10 381-387. (doi:10.1016/S1071-5576(03)00141-2)

Wielockx B, Libert C \& Wilson C 2004 Matrilysin (matrix metalloproteinase-7): a new promising drug target in cancer and inflammation? Cytokine \& Growth Factor Reviews 15 111-115. (doi:10.1016/j.cytogfr. 2003.12.001)

Wolf K, Wu YI, Liu Y, Geiger J, Tam E, Overall C, Stack MS \& FriedI P 2007 Multi-step pericellular proteolysis controls the transition from individual to collective cancer cell invasion. Nature Cell Biology 9 893-904. (doi:10.1038/ncb1616)

Zhang GY, Ahmed N, Riley C, Oliva K, Barker G, Quinn MA \& Rice GE 2005 Enhanced expression of peroxisome proliferator-activated receptor gamma in epithelial ovarian carcinoma. British Journal of Cancer 92 113-119. (doi:10.1038/sj.bjc.6602244)
Zhao YG, Xiao AZ, Ni J, Man YG \& Sang QX 2009 Expression of matrix metalloproteinase-26 in multiple human cancer tissues and smooth muscle cells. Ai Zheng 28 1168-1175.

Zucker S, Drews M, Conner C, Foda HD, DeClerck YA, Langley KE, Bahou WF, Docherty AJ \& Cao J 1998 Tissue inhibitor of metalloproteinase-2 (TIMP-2) binds to the catalytic domain of the cell surface receptor, membrane type 1-matrix metalloproteinase 1 (MT1-MMP). Journal of Biological Chemistry 273 1216-1222. (doi:10.1074/jbc.273.2.1216)

Received 14 October 2014

First decision 1 December 2014

Revised manuscript received 30 March 2015

Accepted 24 April 2015 